\title{
Scaling major transitions in human sociopolitical complexity
}

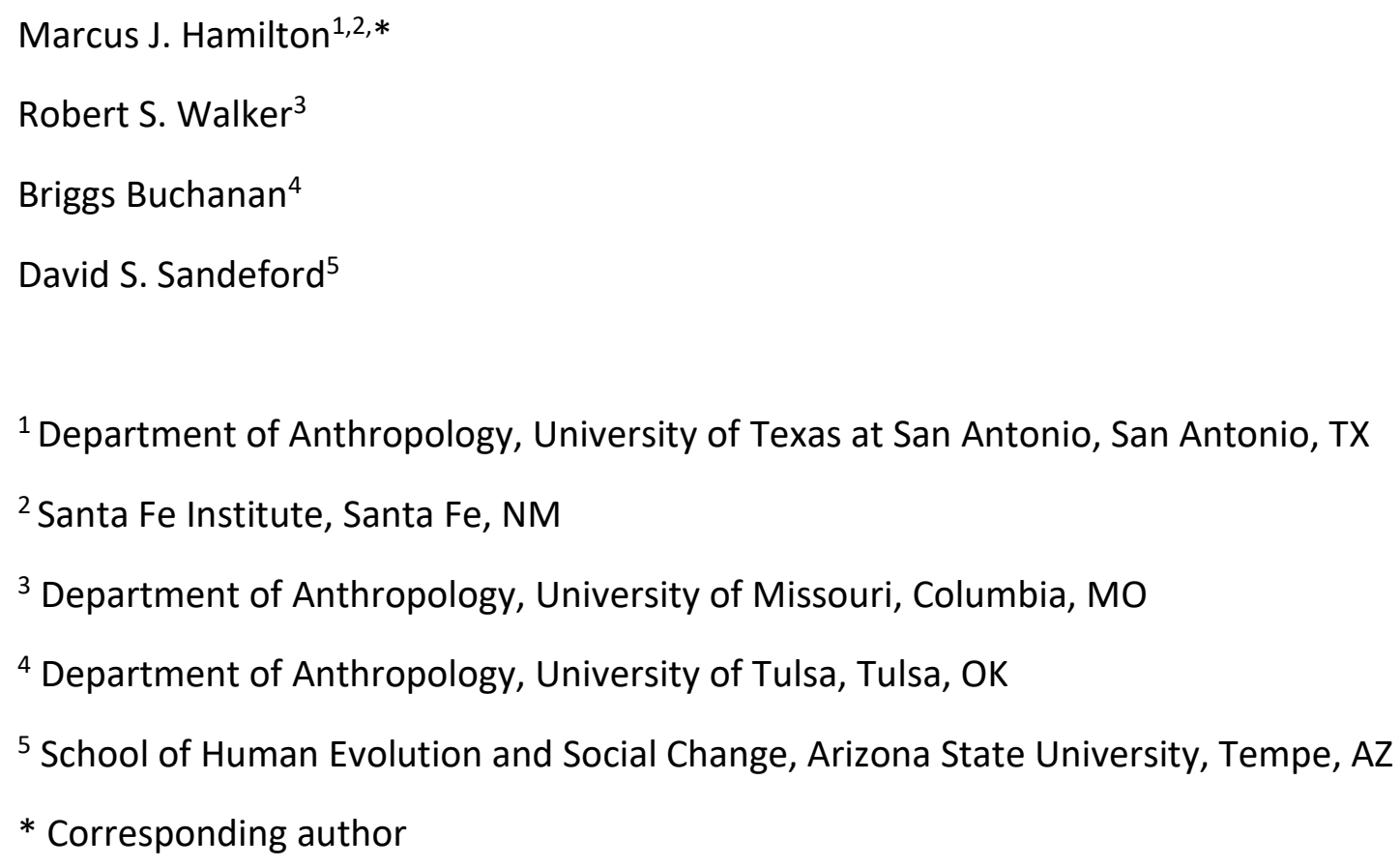




\begin{abstract}
The human species is diverse in the size, structure and complexity of our social organizations. Today, human sociopolitical complexity ranges from stateless small-scale societies to complex states that integrate millions of individuals over vast geographic areas. Here, we explore major transitions across this range of complexity. In particular, we examine the statistical structure of these transitions using Horton-Strahler branching, generalized Horton Laws, and allometric spatial mixed-effect models. We show that all major transitions in sociopolitical complexity follow an invariant fractal-like growth process; with each transition there is an additional level of jurisdictional hierarchy, a four-fold increase in population size, a two-fold increase in population area, and therefore a doubling of population density. These statistics fully describe all transitions from the least to the most complex societies. However, these transitions are probabilistic, not deterministic in nature. This fact explains the asymmetry of human sociopolitical evolution: while more complex societies were necessarily once less complex, less complex societies do not necessarily become more complex.
\end{abstract}




\section{Introduction}

Human societies display a wide diversity of sociopolitical complexity. In the $21^{\text {st }}$ century, at the smallest scale we might find autonomous hunter-gatherer families operating in parts of Africa, or villages of horticulturalists in New Guinea pursuing predominantly subsistence lifestyles with varying levels of interaction with market economies. There are still several dozen isolated populations on the planet with little to no effective interaction with the outside world [1-5]. The smallest-scale societies are often organized into flexible, politically-autonomous, and egalitarian groups of perhaps a few dozen individuals integrated into larger ethnolinguistic metapopulations often on the scale of hundreds to a few thousand people. For example, the Hadza huntergatherers of Tanzania have a total population size of $\sim 1,000$, divided into four geographic regions, where individual families form residentially mobile bands of $\sim 20$ co-residing individuals [6]. At the other end of the spectrum, the largest human organizations are complex states, often comprised of millions of people structured in space by hierarchical networks of cities, towns, villages, and farms, with diverse economies and hierarchically nested political institutions. For example, the United States has a population of 327 million divided into 50 states with a dozen cities of populations greater than a million, and a political hierarchy composed of cities, municipalities, counties, states, and the federal government [7].

This range of sociopolitical diversity evolved only recently in human evolutionary history. Beginning with the development of agricultural food production $\sim 11,000$ years ago in the ancient Near East and elsewhere in various regions of the planet shortly thereafter, many populations who were previously mobile egalitarian hunter-gatherers incorporated agricultural foods into their diets and became increasingly residentially sedentary, economically diverse, and politically nonegalitarian. The first complex states in the ancient world began to appear $\sim 6,000$ years ago in agriculturally productive areas of the planet, including southern Mesopotamia, Egypt, the Indus Valley, China, and later various parts of the Americas [8-12]. The current scale of diversity we see today in human sociopolitical complexity ultimately was fueled by the industrial revolution, which led to increased population growth supported by industrialized agriculture, the expansion of global markets, and increased rates of technological and scientific innovation resulting in even greater economic, political, and cultural asymmetries among larger and ever more complex societies.

An axiomatic feature of the archaeological, ethnographic, and historical record is that more complex societies were once less complex: the earliest states were regional polities that emerged from networks of local villages, which were formed by farmers who were hunter-gatherers prior to the adoption of domesticated plants and animals [13]. Similarly, the 195 member state countries of the United Nations each emerged from a long series of economic, political, and historical processes that integrated once politically-autonomous societies that emerged themselves from previously politically-autonomous entities, and so on. A conspicuous feature in the evolution of this diversity is the quantitative and qualitative nature of transitions in sociopolitical complexity across these different scales. Clearly, the United States is not simply a 
vast conglomeration of 327 million hunter-gatherers, nor is a Hadza band a microcosm of the Tanzanian state.

A well-documented feature of human social systems at all scales is the modular and hierarchical organization of the social networks that underlie their structure [10,13-17]. Examples of this property of human social organization include hunter-gatherer social networks $[14,15,18]$, smallscale autonomous village societies [17,19], the infrastructure of both ancient and modern cities [20-23], the internal organization of ancient states and empires [10], and the personal, political, scientific, communication, and financial networks that form the institutional infrstructure of modern nation-states [22,24-34]. Despite this emerging insight into the fundamental structure of human social organization, little is known quantitatively about the nature of the transitions between different levels of sociopolitical complexity. Are there general statistics to these transitions that suggest critical behavior in changes of state common to the evolution of complex systems, or is each transition in complexity unique in time and space, the result of local conditions and historically-contingent events?

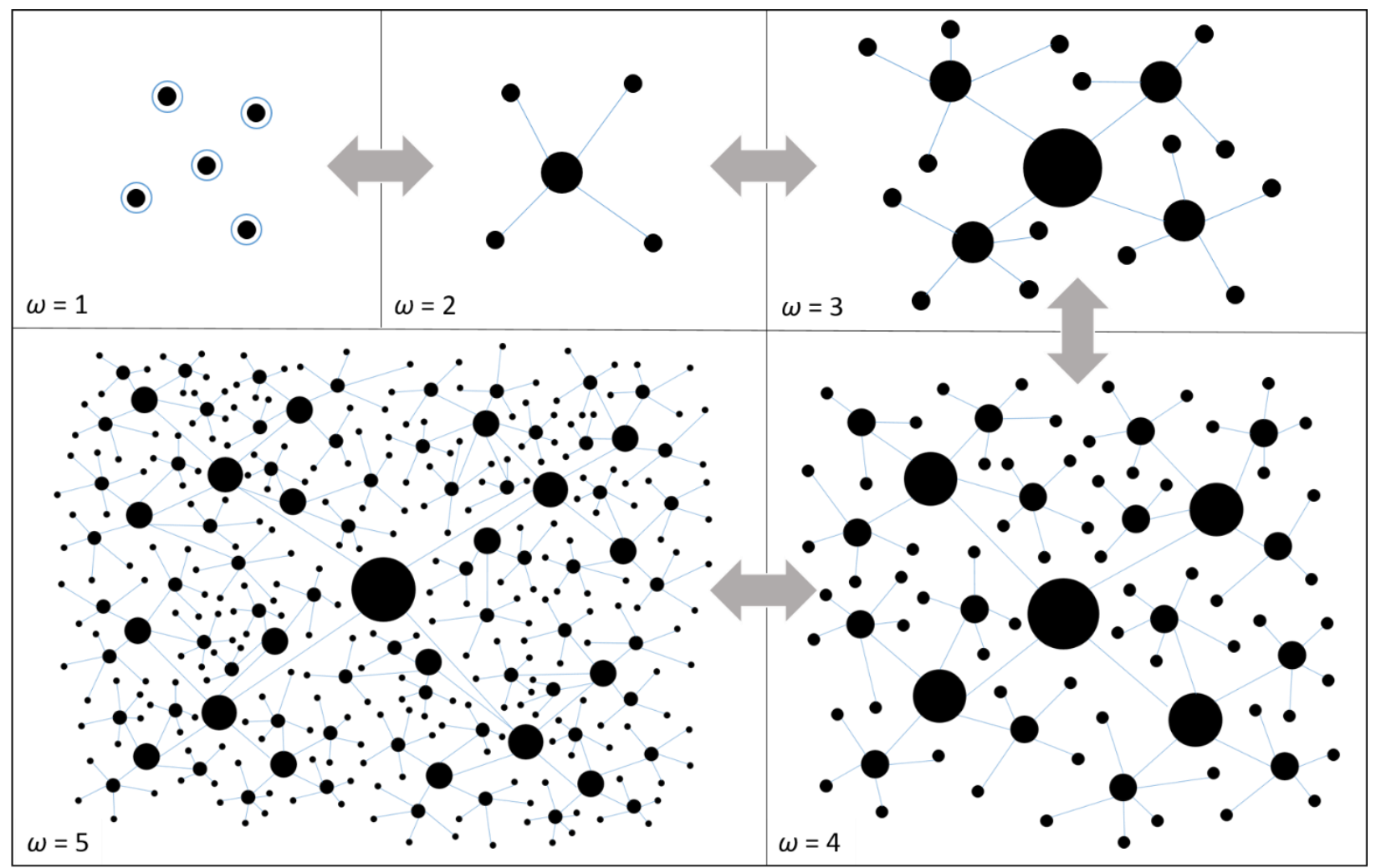

Figure 1. A schematic of the various scales of jurisdictional hierarchy in human sociopolitical complexity, from $\omega=1$, the smallest scale politically-autonomous societies, to $\omega=5$, the most complex state societies with five levels of sociopolitical and spatial hierarchy. In each panel there is an approximate 4-fold increase in the connected population size and an approximate 2-fold increase in population area, and so a doubling of population density. 
Here, we quantify transitions in the sociopolitical complexity of human societies using scaling statistics, including Horton-Strahler branching, generalized Horton Laws, and allometric mixed models $[15,35]$. A common metric of sociopolitical complexity used across the social sciences is the level of jurisdictional hierarchy beyond the local community recognized by a society, as recorded in the Ethnographic Atlas [36,37]. Sociopolitical complexity, $\omega$, ranges in scale from 1 to 5 , where 1 is the minimal condition of a stateless acephalous society (i.e., the Hadza, who recognize no formal jurisdictional hierarchy beyond the local group) and 5 is a multi-tiered hierarchical state (i.e., the US, where there is a formal jurisdictional hierarchy at multiple levels, from local communities to the federal government) (Figure 1). We focus primarily on the scaling of population size, $N$, spatial extent (i.e., area) $A$, and population density, $D=N / A$ across these 5 levels of complexity both in terms of their average properties and the scaling of their entire probability distributions.

Horton-Strahler branching ratios. First, we quantify transitions between levels by calculating the branching ratios of population sizes and areas from the data. Let $N_{i, \omega}$ be the size $N$ of the ith population at level $\omega$, and let $A_{i, \omega}$ be the area $A\left(\mathrm{in}^{2}{ }^{2}\right.$ ) of the ith population at level $\omega$ (termed the Horton order). To calculate the branching ratio we first define $N_{\omega}^{*}=\exp \left(\left\langle\ln N_{\omega}\right\rangle\right)$ as the multiplicative mean (or geometric mean) population size at the $\omega$ th level (where $\langle\cdot\rangle$ denotes a mean), and $A_{\omega}^{*}=\exp \left(\left\langle\ln A_{\omega}\right\rangle\right)$ as the multiplicative mean population area at the $\omega$ th level. For population sizes, we then define the Horton-Strahler branching ratio, $R_{N}$ as ratio of multiplicative means between levels:

$$
R_{N} \equiv \frac{N_{\omega+1}^{*}}{N_{\omega}^{*}} .
$$

For population areas we define the branching ratio, $R_{A}$ as

$$
R_{A} \equiv \frac{A_{\omega+1}^{*}}{A_{\omega}^{*}} .
$$

We calculate the branching ratios between all levels. If the branching ratios are constant across all transitions then the structure is considered to be statistically self-similar. Rearranging equations 1 and 2 we then have 


$$
N_{\omega+k}^{*}=N_{\omega}^{*} e^{\lambda k}
$$

And

$$
A_{\omega+k}^{*}=A_{\omega}^{*} e^{\gamma k}
$$

Where $k=\Delta \omega, \lambda=\ln R_{N}$ and $\gamma=\ln R_{A}$. Therefore, if self-similar a semi-log plot between $N_{\omega}^{*}$ and $\omega$ will be well-fit by a straight line of slope $\lambda$, and a semi-log plot of $A_{\omega}^{*}$ and $\omega$ will be wellfit by a straight line of slope $\gamma$.
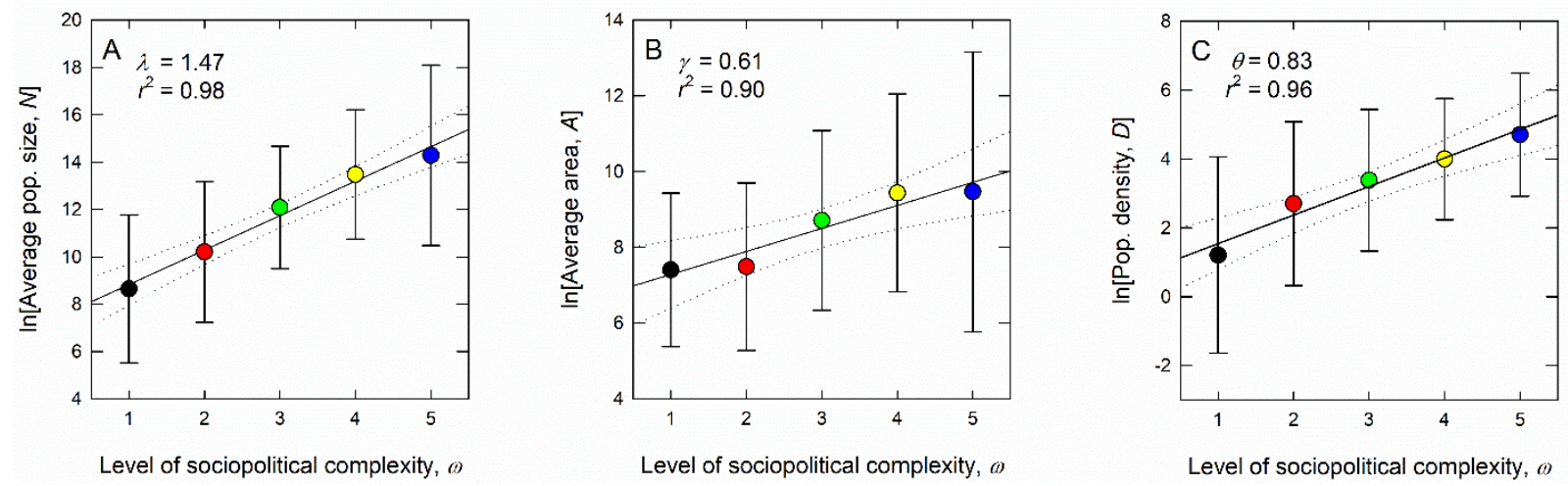

Figure 2. Means and standard deviations of ethnolinguistic population sizes (A), areas (B), and population density (C) by level of sociopolitical complexity. The color coding is followed throughout the paper. The solid black lines are regression fits and the dotted lines are 95\% confidence intervals around the slope. Despite the overlap in data among classes in all plots all means are well-fit by the regression models and fall within the $95 \%$ confidence intervals. Statistical errors around parameter estimates are reported in the text.

The mean sizes, variation, and confidence limits for the population size and area data are given in Table 1 and shown in Figure 2. Average population sizes range from $\sim 5,600$ at $\omega=1$ to $\sim 1.6$ million at $\omega=5$, a 280-fold increase. Average areas range from $\sim 1,600 \mathrm{~km}^{2}$ at $\omega=1$ to $\sim 13,000$ $\mathrm{km}^{2}$ at $\omega=5$, an 8-fold increase across the range. Figures $2 \mathrm{~A}$ and $B$ show the semi-log plots of average population size, $\ln N$, and area, $\ln A$, as functions of sociopolitical level, $\omega$. Both semilog plots are well-fit by linear functions as all the means are encompassed by the $95 \%$ confidence interval around the slope, with high $r^{2}$ values. The population branching ratio is $R_{N}=\exp (\lambda)=4.29(3.02-6.11)$, and the area branching ratio is $R_{A}=\exp (\gamma)=1.84(1.28-6.23)$ - Consequently, with each transition in sociopolitical complexity population density 
approximately doubles, as is shown in Figure $2 \mathrm{C}$ where $\theta=0.83( \pm 0.10)$ and so $\exp (\theta)=2.29(1.68-3.11)$. On average, each transition in sociopolitical complexity is associated with an additional level of jurisdictional hierarchy, a four-fold increase in population size, a twofold increase in spatial extent, and a doubling of population density. However, note that in Figures $2 \mathrm{~A}-\mathrm{C}$ there is considerable overlap in the size, area, and density of populations across the five scales indicating that transitions are in no sense deterministic, but probabilistic.

Table 1. Descriptive statistics for the population size and area data by sociopolitical level.

\begin{tabular}{|c|c|c|c|c|c|c|}
\hline Level & Sample size & Mean $\ln [$ pop. size] & s.d. & Geomean pop. size & $95 \% \mathrm{CL}$ & $95 \% \mathrm{CL}$ \\
\hline$\omega$ & $n$ & $\left\langle\ln N_{\omega}\right\rangle$ & $\sigma_{\ln N}$ & $N_{\omega}^{*}$ & Lower & Upper \\
\hline 1 & 417 & 8.64 & 3.12 & 5,663 & 4,197 & 7,641 \\
\hline 2 & 354 & 10.20 & 2.97 & 27,028 & 19,830 & 36,838 \\
\hline 3 & 187 & 12.08 & 2.59 & 177,106 & 122,230 & 256,620 \\
\hline 4 & 140 & 13.48 & 2.73 & 713,318 & 453,540 & $1,121,893$ \\
\hline 5 & 30 & 14.29 & 3.81 & $1,599,611$ & 408,630 & $6,261,798$ \\
\hline Level & Sample size & Mean $\ln [$ Area] & s.d. & Geomean area & $95 \% \mathrm{CL}$ & $95 \% \mathrm{CL}$ \\
\hline$\omega$ & $n$ & $\left\langle\ln A_{\omega}\right\rangle$ & $\sigma_{\ln A}$ & $A_{\omega}^{*}$ & Lower & Upper \\
\hline 1 & 430 & 7.40 & 2.03 & 1,639 & 1,354 & 1,986 \\
\hline 2 & 363 & 7.49 & 2.21 & 1,784 & 1,421 & 2,240 \\
\hline 3 & 191 & 8.71 & 2.37 & 6,070 & 4,335 & 8,499 \\
\hline 4 & 142 & 9.43 & 2.61 & 12,514 & 8,145 & 19,228 \\
\hline 5 & 31 & 9.47 & 3.70 & 12,946 & 3,525 & 47,542 \\
\hline
\end{tabular}

Rescaling and data collapse. To understand whether this scaling behavior is limited to averages or whether it is a general property of the entire system of transitions, we now consider the scaling of all statistical moments of the probability distributions of $N$ and $A$ using generalized Horton Laws [38]. We define $p\left(N_{\omega}\right)$ and $p\left(A_{\omega}\right)$ as the probability distributions of $N$ and $A$ of all populations at the $\omega$ th level. If sociopolitical structure is self-similar in population size $N$ and area $A$ then the probability distributions at each level vary by some scalar $\kappa$, and so $p\left(N_{\omega+1}\right)=p\left(N_{\omega}\right) \kappa$ and $p\left(A_{\omega+1}\right)=p\left(A_{\omega}\right) \kappa$. The Horton-Strahler analysis suggests this scalar is the multiplicative mean of the distribution. Therefore, by rescaling each population size $N_{i, \omega}$ and area $A_{i, \omega}$ by their respective multiplicative means $N_{\omega}^{*}$ and $A_{\omega}^{*}$ we non-dimensionalize the data defining the rescaled quantities, $N_{i, \omega}^{\prime} \equiv N_{i, \omega} / N_{\omega}^{*}$ and $A_{i, \omega}^{\prime} \equiv A_{i, \omega} / A_{\omega}^{*}$. Theory predicts that if the entire distributions are self-similar at all moments then both population size and area should collapse onto unique non-dimensional scaling functions. Indeed, Figure 3 shows that in both cases, all data collapse onto single scaling functions, indicating that the entire distributions of population sizes and areas are self-similar. The major transitions in sociopolitical complexity, 
from autonomous small-scale village-level societies to politically-complex hierarchical states are a series of self-similar transitions.
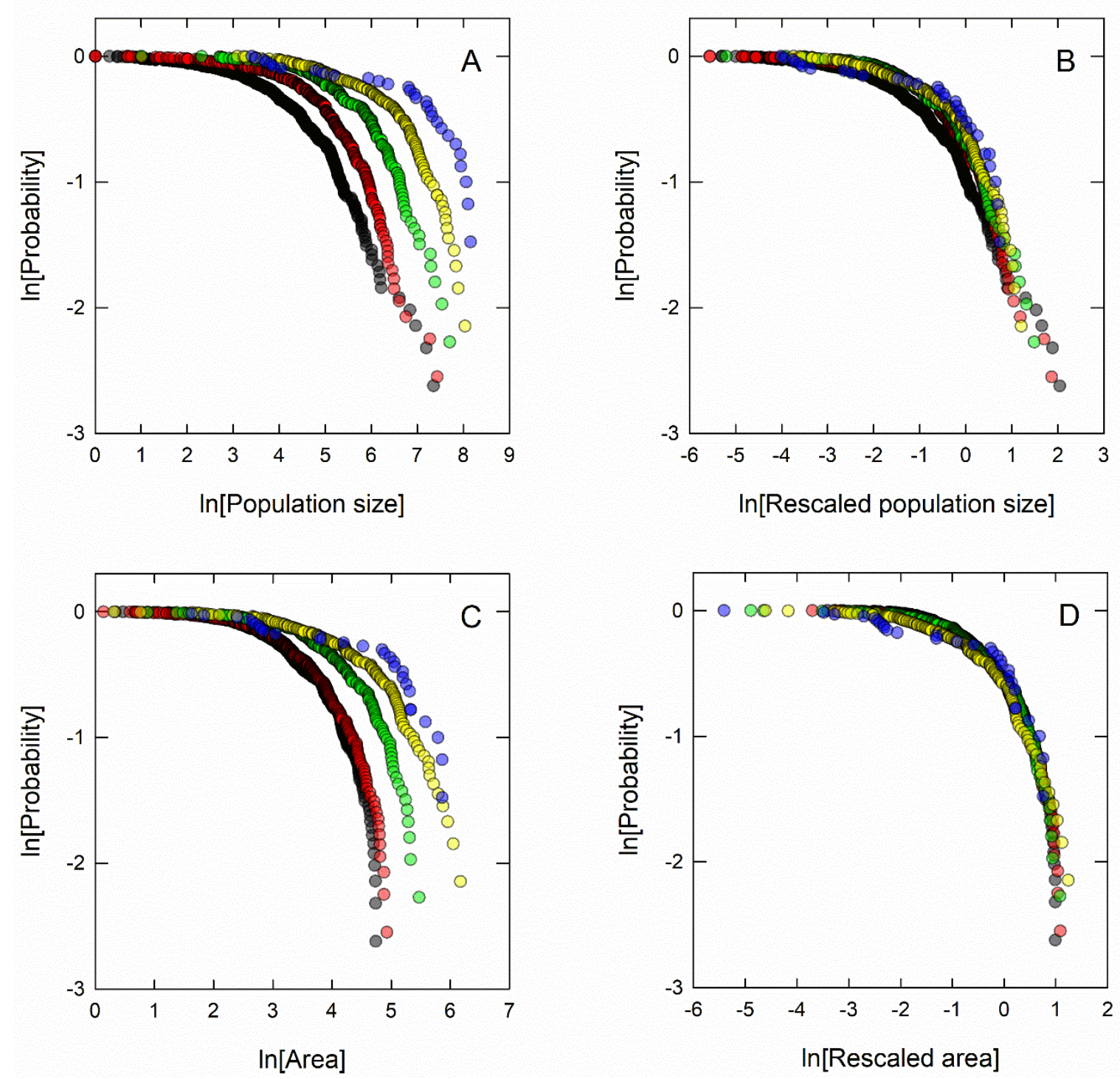

Figure 3. Data collapse of population sizes and areas across the five levels of sociopolitical complexity using Generalized Horton Laws: A) Probability distributions of the raw population size data; B) rescaled population size data; C) probability distributions of the raw population area data; and D) rescaled population area data. The color scheme follows Figure 2.

Fractal dimension. Self-similarity is a statistical characteristic of a scale invariant fractal process [39]. As both the branching ratios of population sizes and areas are self-similar then the major transitions in sociopolitical complexity are fractal in nature. This fractality is captured by the Haussdorf dimension, $H$, which we estimate from the data in three ways: 
First, from the definition of the fractal dimension as the ratio of the characteristic branching processes of the system we have:

$$
H=\frac{\ln R_{N}}{\ln R_{A}}=\frac{\lambda}{\gamma}=\frac{1.46}{0.61}=2.39
$$

Second, estimating the fractal dimension as the ratio of the logarithm of the mean branching ratios across the four transitions we have:

$$
H=\frac{\ln \left\langle R_{N}\right\rangle}{\ln \left\langle R_{A}\right\rangle}=\frac{\ln 4.40}{\ln 1.90}=2.31
$$

And third, estimating the fractal dimension $H=d \ln \left\langle N_{\omega}\right\rangle / d \ln \left\langle A_{\omega}\right\rangle$ by fitting a slope to a loglog plot of average population size and average area per level of sociopolitical complexity we find $H=2.24(1.24-3.24$ ) (Figure 4). In all three cases the fractal dimension is estimated between 2.2-2.4, but with wide confidence limits. Thus population density across scales of sociopolitical complexity has a fractal dimension of $H \approx 2$. Moreover, the fractal nature of population density indicates that population structure is statistically invariant across levels. This property is depicted visually in Figure 1 where each new additional level is ultimately a rescaled version of the previous level, which, in this case includes a four-fold increase in population size and a two-fold increase in spatial extent. 


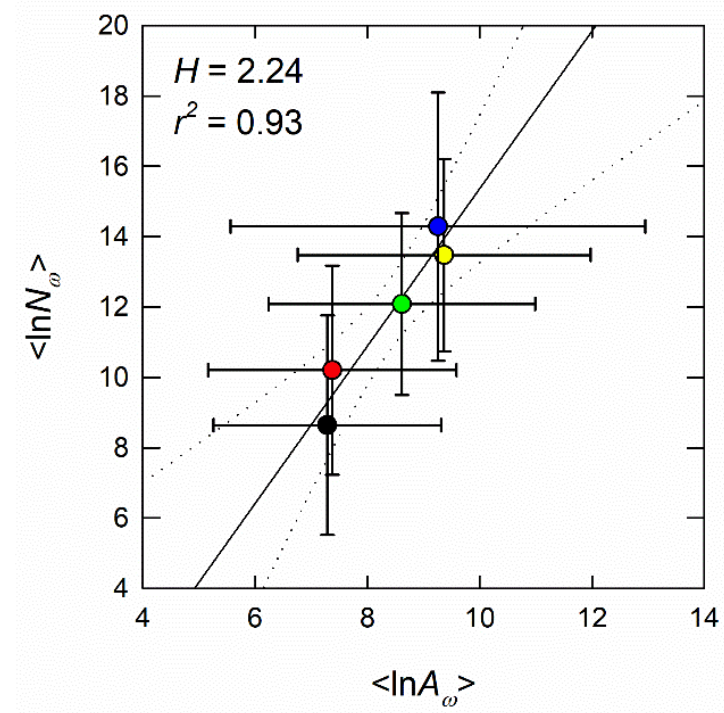

Figure 4. Log-log plot of the average population size per level, $\left\langle\ln N_{\omega}\right\rangle$, by the average area per level, $\left\langle\ln A_{\omega}\right\rangle$.

Allometry. We further investigate how population density changes with sociopolitical complexity by examining the allometric scaling of population size and area. As both $N$ and $A$ are functions of scale, $\omega$, we derive the allometric scaling of $A \propto N$ from equations 3 and 4 to yield the standard scaling equation

$A=A_{0} N^{\beta}$

where $\beta=\gamma / \lambda=\ln R_{A} / \ln R_{N}=1 / H$ and $A_{0}$ is a normalization constant. At each level of sociopolitical complexity we then have

$A_{\omega}=A_{0, \omega} N_{\omega}^{\beta_{\omega}}$

Because equation 6 explicitly describes the relationship between the area and size of a population, it is a fundamental description of the spatial ecology of populations at each level of sociopolitical complexity. As $A_{0}=A N^{-\beta}$ it is also the area per individual when $N=1$. In huntergatherer populations, the area per individual is determined largely by the space required to meet metabolic demand and the packing of individuals in space. However, as subsistence technology 
diversifies to include agricultural production area per individual tends to decrease as agriculture increases the productivity per unit area [40-42]. Figure 5A shows that although dependence on agriculture seems to saturate at the highest levels of sociopolitical complexity, on average there is $\sim 10 \%$ increase in the dependence of agriculture with increasing level of sociopolitical complexity and Figure 5B shows that average population density at each level increases by $8 \%$ with each percentage increase in agricultural dependence. Therefore, a $10 \%$ increase in the dependence of agriculture is correlated with a doubling of population density.

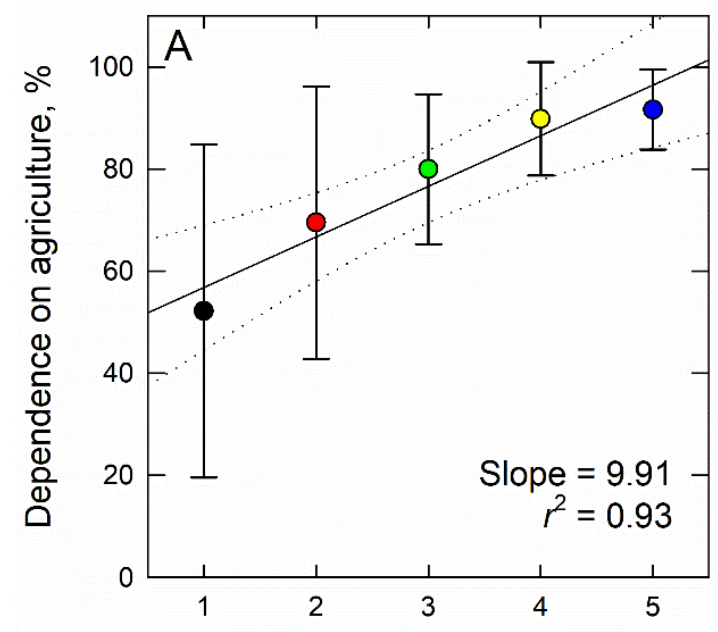

Level of sociopolitical complexity, $\omega$

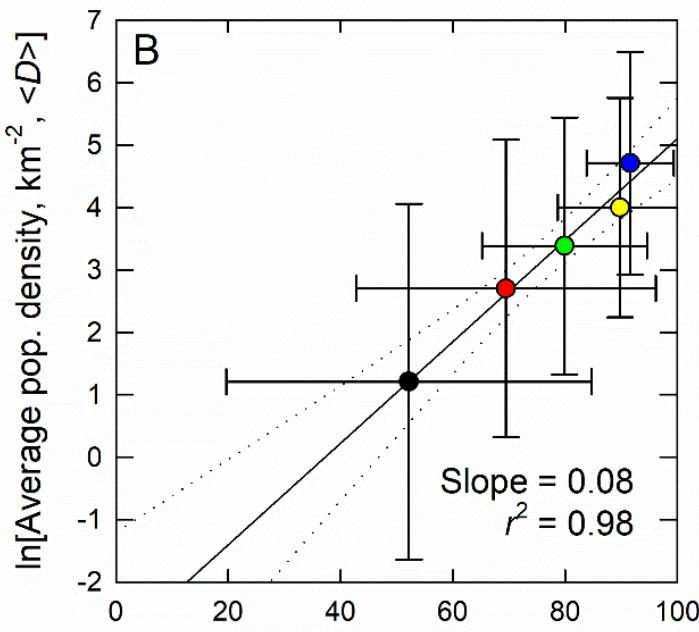

Dependence on agriculture, $\%$

Figure 5. The dependence on agriculture across the range of sociopolitical complexity. A) The mean and standard deviation of dependence on agriculture by levels of sociopolitical complexity; and B) Average population density per level of sociopolitical complexity by dependence on agriculture. Population density increase $8 \%$ per $1 \%$ increase in the dependence on agriculture.

We model the scaling of population density across levels of sociopolitical complexity and the interaction of agriculture using a spatial mixed-effect model (spaMM) [43-45], which controls for spatial autocorrelation and the evolutionary nested structure of ethnolinguistic populations within languages within language families in both continuous and categorical variables. Goodness-of-fit is estimated using out-of-sample cross validation (see Methods below). Note, if $H \approx 2$ then $\beta=1 / H \approx 1 / 2$. Results show that the overall scaling of area and population size across all levels is $\beta=0.48\left( \pm 0.06, r^{2}=0.70 \%\right)$. Figures $6 \mathrm{~A}-\mathrm{E}$ show the log-log scaling of area, $A$, and population size, $N$, for the five levels of sociopolitical complexity, $\omega$. Figure $6 \mathrm{~F}$ shows that the scaling slope, $\beta_{\omega}$, increases as the area per individual, $A_{0, \omega}$, decreases. This means that there is a fundamental trade-off in the scaling of human spatial ecology across the range of sociopolitical complexity. As populations increase in sociopolitical complexity the area per individual decreases rapidly as technological innovations in agricultural technology increase the 
productivity per unit area, but there is less overlap in space in complex societies than less complex societies.
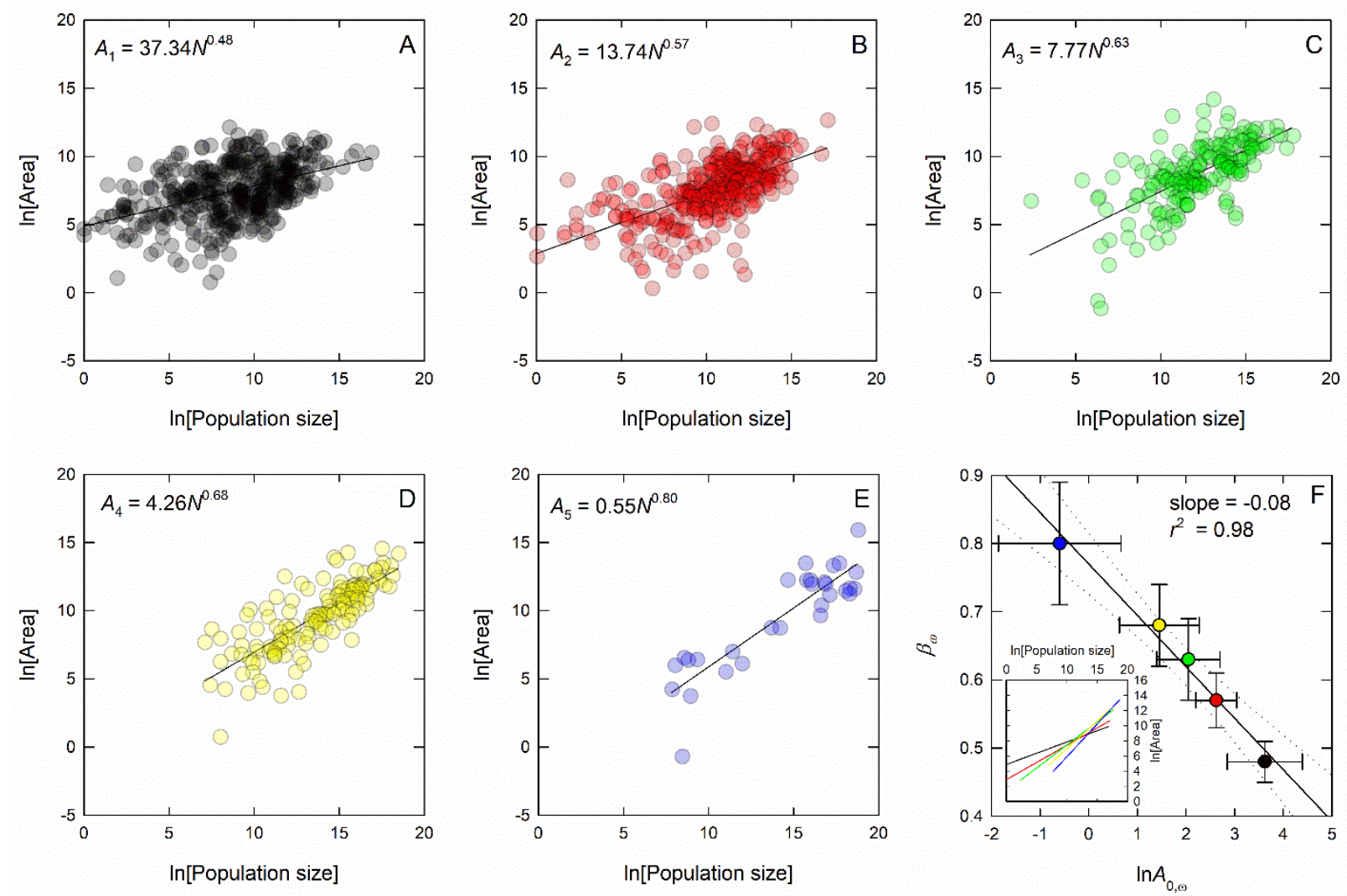

Figure 6. Scaling of ethnolinguistic area, $A$, as a function of population size, $N$ at all scales of sociopolitical complexity. Figures 6A-E show sociopolitical levels 1-5 respectively, the solid lines are the fits estimated from the spatial mixed-effect model (spaMM), and the equations are the parameter estimates. Figure 6F shows the strongly negative relationship between the slopes, $\beta_{\omega}$ , and the intercepts, $A_{0, \omega}$ across levels, and the inset shows the estimated allometries of the fitted model slopes from figures A-E (details are given in the online supplementary materials).

\section{Discussion}

Our results show that major transitions in human sociopolitical complexity are fully-described by a fractal-like, probabilistic, asymmetrical, scale-dependent statistical growth process. Associated with each positive transition we see an increased levels of jurisdiction hierarchy associated with a four-fold increase in population size, a two-fold increase in area, a doubling of population density, and a $\sim 10 \%$ increase in agricultural production. The constant Horton-Strahler branching ratios demonstrate that this growth process is fractal-like and the successful data collapses of all data across all levels show that this fractality fully describes all transitions from the least to the 
most complex societies. The fractality of sociopolitical complexity suggests major transitions are related to critical thresholds in human social organization that are ultimately related to population densities and their economic, technological, and infrastructural networks. Although there are substantial qualitative differences in the nature of human societies across the spectrum of sociopolitical complexity, these statistics show that fundamental aspects of human social structure are invariant to these transitions. That is to say, certain changes in population structure are predictable simply from knowing the level of sociopolitical complexity in a given society.

Importantly, transitions in sociopolitical complexity are probabilistic, not deterministic. As populations approach or surpass certain threshold densities they are increasingly likely to develop an additional level of sociopolitical organization, especially when associated with increased levels of agricultural production. Similarly, as populations fall below density thresholds they are increasingly likely to lose levels of sociopolitical organization. The considerable overlap of population sizes, areas, and densities across the range of sociopolitical complexity shown in Figure 2 highlights the statistical nature of these thresholds. This means that transitions are not governed solely by endogenous growth mechanisms, but by the interaction of endogenous growth with an array of exogenous constraints. These constraints include: local environmental productivity; the availability of agricultural technology; the density, structure, and nature of interactions with neighboring societies, as well as all other sources of historical contingency and environmental stochasticity. All these factors combine to impact the level and trajectory of sociopolitical complexity experienced locally in a society. Ultimately all transitions in human sociopolitical complexity involve qualitative shifts in the form of sociopolitical leadership, infrastructure networks, settlement patterns, technological innovations, economic productivity and economic specialization that result from the complex interactions, correlations, and feedbacks that build among systems over time and space. However, the fundamental population structure over which these interactions play out is statistically invariant.

The statistical nature of these transitions also explains the inherent asymmetry of the evolution of human sociopolitical complexity. While it is axiomatic that societies with increased levels of sociopolitical complexity evolved from societies that were once less complex (i.e., smaller in size, more local in scale, and less dense) the reverse is clearly not true. As populations grow and foodproduction technologies develop less complex societies do not necessarily develop additional levels of complexity deterministically, but they are increasingly likely to do so. Additionally, while there has been a net increase in the average sociopolitical complexity of human societies over the Holocene, this trajectory is not only asymmetric but nonlinear; human societies commonly cycle through periods of growth, stability, and collapse [46], often associated with major transitions in sociopolitical complexity $[47,48]$.

The scale-dependent allometric scaling of population size, area, and density show that the dynamics of population density are a function of sociopolitical complexity. Figure 6 shows that the scaling of population size and area becomes steeper and the intercept decreases as the level of sociopolitical complexity increases. As a result, population density increases with population 
size fastest in the most complex societies, and slowest in the least. Therefore, while population density doubles on average with increasing sociopolitical complexity, the differential response of population density to population size is scale-dependent. This result suggests that as agricultural dependence increases with sociopolitical complexity population density increases dramatically but the overall system loses efficiency as the scaling behavior that captures the packing of individuals in space becomes steeper. As societies increase in complexity they also increase in size, infrastructure, and bureaucracy, and so economic returns to scale are increasingly institutional and less demographic, and seemingly less efficient.

What, if anything, does this say about the evolution of human sociopolitical complexity over time? Clearly while there is a correlation between demographic scale and sociopolitical complexity, major transitions in sociopolitical complexity are also transitions in the roles of economic, social, and political institutions [10,13,47-55]. World population size at the end of the Pleistocene was likely on the order of $10-20$ million, increasing with the development of agriculture, but the vast majority of human population growth has occurred over recent decades. Were the first societies to exhibit the first tier of sociopolitical hierarchy beyond their local community about four times as populous as preexisting societies? Were the earliest complex states of the mid-Holocene on the scale of millions of people? Population sizes and densities are notoriously difficult to reconstruct with any certainty from the archaeological record, however, population estimates of early states in the ancient world are often comfortably into the millions [13,56-60]. Recent models of social organization within primary states in the ancient world suggest regional populations in the $10 \mathrm{~s}-100 \mathrm{~s}$ of thousands had internal organizational structures with branching ratios 3-5 [10], remarkably similar to statistics of social networks in the modern world. If so, this further supports the suggestion that the primary branching architecture of human social organization may be invariant. However, the population sizes at each level of sociopolitical complexity increased at differential rates with the explosive growth of human populations over recent decades. For example, today the total population size of the Hadza is $\sim 1,000$, close to the average size of other ethnographic hunter-gatherer populations [15]. Regional population sizes of hunter-gatherers in the late Pleistocene hunter-gatherer world were probably of a similar scale, at least not orders of magnitude different in size. However, the same is not true for cities. The first cities to appear in the ancient Near East likely had populations on the order of a few tens of thousands [61], several orders of magnitude smaller than cities today. The scale of the first major cities in the ancient world would barely be counted as small towns today, and the largest contemporary cities such as Tokyo, Delhi, Shanghai, or Mexico City (all over 20 million) now house the equivalent of the entire human species for most of human evolutionary history.

While major transitions in sociopolitical complexity are clearly associated with population size and structure, the directionality of causation is not straightforward. Political centralization and growing socioeconomic asymmetries impact human societies in complex ways. Is it the case that societies with increasingly formalized sociopolitical infrastructures have a greater likelihood of growing in size and space? Or is it the case that more technologically innovative societies have 
greater potential for growth in size and space and are thus more likely to develop additional levels of sociopolitical complexity? Or perhaps there is no clear linear causality; as deeply intercorrelated traits interact to impact the size, density, economy, and organization of populations, complex nonlinear feedbacks are set in place that, in time, result in major transitions to new levels of sociopolitical complexity.

\section{Methods and data}

Ethnolinguistic populations are among the largest scales of human social organization. Our primary unit of analysis is ethnolinguistic area, $A$, which is a spatially and linguistically discrete region of the planet's surface measured in units of $\mathrm{km}^{2}$ and inhabited by $N$ individuals. Sizes and areas vary widely, from a handful of speakers covering an area of a few square kilometers, to many millions of speakers covering hundreds of thousands of square kilometers. Multiple ethnolinguistic areas may share a common language, $L$. Ethnolinguistic area polygons $(N=7,627)$ were downloaded as shapefiles from the Ethnologue. For each ethnolinguistic polygon we first searched for matching linguistic names in the Ethnographic Atlas. For every ethnolinguistic polygon with no direct match with the Ethnographic Atlas we then conducted an online search for alternative names for languages, alternate spellings, or tribal affiliations. We were able to match 1,284 ethnolinguistic polygons with the Ethnographic Atlas. We made a total of 964 total matches between language names across data sets, but as languages are often spoken in more than one ethnolinguistic area, the total number of polygons increased to 1,284. To control for this clustering, we used language name, $L$, as a random effect in our models. Using the Ethnographic Atlas, for each ethnolinguistic area we recorded language name, $L$, language family, $F$, the continent on which it occurs, $C$, percentage dependence on agriculture, $G$, and the level of sociopolitical complexity, $\omega$.

To analyze these data, we used a combination of Horton-Strahler ordering, generalized Horton Laws and allometric scaling approaches. Generalized Horton Laws are used to characterize the hierarchical branching structure of complex networks throughout the sciences [38]. Each sociopolitical level is assigned a hierarchical order, $\omega$, where $\omega \in(1,5)$, which in Horton analysis is termed the Horton order. Each ethnolinguistic population is then assigned to the sociopolitical level, $\omega$, as given by the Ethnographic Atlas. In the Ethnographic Atlas the level of sociopolitical complexity comes from table 33 "Jurisdictional Hierarchy Beyond Local Community", which Murdoch defines as the level of sociopolitical complexity, ranging from 1-5, where 1 = no political authority beyond community; 2 = simple chiefdoms; 3 = complex chiefdoms; 4 = early states; and $5=$ large states. The integers refer to the levels of jurisdictional hierarchy.

Allometric models were constructed using spatial mixed-effect models, or spaMMs [43-45]. These were run in $\mathrm{R}$ [62]. Here, the dependent variable was area, $A$, and the independent variable was an ethnolinguistic population of size, $N$. Each ethnolinguistic population has a level of sociopolitical complexity, $\omega$, a \% dependence on agriculture, $G$, speaks a language, $L$, (which may 
or may not be common to other ethnolinguistic populations), belongs to a language family, $F$, that occurs in a continent, $C$, which are all potentially correlated in space. SpaMMs model this scaling relationship while controlling for the spatial-autocorrelation of both continuous and discrete variables, which themselves are hierarchically nested. To estimate goodness-of-fit statistics we used out-of-sample cross validation. Here, the data is randomly divided into two sections; a training set of $70 \%$ of the data, and a test set of $30 \%$ of the data. The statistical models are built using the training set and are then evaluated on their ability to predict the out-of-sample test data. Data and results are available in the online supplementary material.

\section{Funding}

The authors have no funding sources to report.

\section{References}

1. Walker RS, Hamilton MJ. 2014 Amazonian societies on the brink of extinction. American Journal of Human Biology 26, 570-572.

2. Walker RS, Hamilton MJ. 2019 Machine learning with remote sensing data to locate uncontacted indigenous villages in Amazonia. PeerJ Computer Science 5, e170.

3. Walker RS, Kesler DC, Hill KR. 2016 Are isolated indigenous populations headed toward extinction? PloS one 11, e0150987.

4. Kesler DC, Walker RS. 2015 Geographic distribution of isolated indigenous societies in Amazonia and the efficacy of indigenous territories. PloS one 10, e0125113.

5. Walker RS, Hill KR. 2015 Protecting isolated tribes. Science 348, 1061-1061. (doi:10.1126/science.aac6540)

6. Marlowe F. 2010 The Hadza: Hunter-Gatherers of Tanzania. Univ of California Press.

7. In press. The World Factbook - Central Intelligence Agency. See https://www.cia.gov/library/publications/the-world-factbook/ (accessed on 6 September 2019).

8. Trigger BG. 2003 Understanding early civilizations: a comparative study. Cambridge University Press.

9. Scott JC. 2017 Against the Grain: A Deep History of the Earliest States. New Haven: Yale University Press.

10. Sandeford DS. 2018 Organizational complexity and demographic scale in primary states. Royal Society Open Science 5, 171137.

11. Diamond JM. 1998 Guns, germs and steel: a short history of everybody for the last 13,000 years. Random House. 
12. Wenke RJ, Olszewski D. 1990 Patterns in prehistory: humankind's first three million years. Oxford University Press New York.

13. Johnson AW, Earle TK. 2000 The evolution of human societies: from foraging group to agrarian state. Stanford University Press.

14. Zhou W-X, Sornette D, Hill RA, Dunbar RI. 2005 Discrete hierarchical organization of social group sizes. Proceedings of the Royal Society of London B: Biological Sciences 272, 439-444.

15. Hamilton MJ, Milne BT, Walker RS, Burger O, Brown JH. 2007 The complex structure of huntergatherer social networks. Proc Roy Soc B 274, 2195-2203. (doi:10.1098/rspb.2007.0564)

16. Dubreuil B. 2010 Human evolution and the origins of hierarchies: the state of nature. Cambridge University Press.

17. Dunbar RIM, Sosis R. 2018 Optimising human community sizes. Evolution and Human Behavior 39, 106-111. (doi:10.1016/j.evolhumbehav.2017.11.001)

18. Lehmann J, Lee P, Dunbar RI. 2014 Unravelling the function of communitylevel organization. Lucy to language: the benchmark papers , 245.

19. Grove M. 2010 Stone circles and the structure of Bronze Age society. Journal of Archaeological Science 37, 2612-2621.

20. Ortman SG, Cabaniss AH, Sturm JO, Bettencourt LM. 2015 Settlement scaling and increasing returns in an ancient society. Science Advances 1, e1400066.

21. Cesaretti R, Lobo J, Bettencourt LM, Ortman SG, Smith ME. 2016 Population-area relationship for Medieval European cities. PloS one 11, e0162678.

22. Bettencourt LM. 2013 The origins of scaling in cities. Science 340, 1438-1441.

23. Bettencourt LMA, Lobo J, Helbing D, Kühnert C, West GB. 2007 Growth, innovation, scaling, and the pace of life in cities. PNAS 104, 7301-7306. (doi:10.1073/pnas.0610172104)

24. Dunbar RI. 2003 The social brain: mind, language, and society in evolutionary perspective. Annual Review of Anthropology 32, 163-181.

25. Dunbar RIM, Arnaboldi V, Conti M, Passarella A. 2015 The structure of online social networks mirrors those in the offline world. Social Networks 43, 39-47. (doi:10.1016/j.socnet.2015.04.005)

26. Dunbar RI, Shultz S. 2007 Evolution in the social brain. Science 317, 1344-1347.

27. Fuchs B, Sornette D, Thurner S. 2014 Fractal multi-level organisation of human groups in a virtual world. Scientific reports 4.

28. Yamada T, Satoshi N, Takahashi Y. 1994 Horton's and Strahler's laws (natural laws in river networks) in telecommunication networks. Teletraffic Science and Engineering 1, 1455-1464. 
29. Vandermarliere B, Ryckebusch J, Schoors K, Cauwels P, Sornette D. 2017 Discrete hierarchy of sizes and performances in the exchange-traded fund universe. Physica A: Statistical Mechanics and its Applications 469, 111-123. (doi:10.1016/j.physa.2016.11.084)

30. Klimek P, Diakonova M, Eguíluz VM, Miguel MS, Thurner S. 2016 Dynamical origins of the community structure of an online multi-layer society. New J. Phys. 18, 083045. (doi:10.1088/13672630/18/8/083045)

31. Porter MA, Mucha PJ, Newman MEJ, Warmbrand CM. 2005 A network analysis of committees in the U.S. House of Representatives. PNAS 102, 7057-7062. (doi:10.1073/pnas.0500191102)

32. Guimera R, Danon L, Diaz-Guilera A, Giralt F, Arenas A. 2003 Self-similar community structure in a network of human interactions. Physical review E 68, 065103.

33. Arenas A, Danon L, Dıaz-Guilera A, Gleiser PM, Guimera R. 2004 Community analysis in social networks. Eur. Phys. J. B 38, 373-380.

34. Sutcliffe A, Dunbar R, Binder J, Arrow H. 2012 Relationships and the social brain: integrating psychological and evolutionary perspectives. British journal of psychology 103, 149-168.

35. Rodriguez-Iturbe I, Rinaldo A. 2001 Fractal river basins: chance and self-organization. Cambridge University Press.

36. Murdock GP, Textor R, Barry III H, White DR, Gray JP, Divale W. 1999 2000. Ethnographic atlas. World Cultures 10, 24-136.

37. In press. D-PLACE - Variable Jurisdictional hierarchy beyond local community [EA033]. See https://dplace.org/parameters/EA033\#1/30/152 (accessed on 6 September 2019).

38. Veitzer SA, Gupta VK. 2000 Random self-similar river networks and derivations of generalized Horton Laws in terms of statistical simple scaling. Water Resources Research 36, 1033-1048. (doi:10.1029/1999WR900327)

39. Mandelbrot BB. 1983 The fractal geometry of nature. WH freeman New York.

40. Hamilton MJ, Milne BT, Walker RS, Brown JH. 2007 Nonlinear scaling of space use in human huntergatherers. PNAS 104, 4765-4769.

41. Hamilton MJ, Burger O, Walker RS. 2012 Human ecology. In Metabolic Ecology: A Scaling Approach, pp. 248-257. London: Wiley-Blackwell.

42. Burnside WR, Brown JH, Burger O, Hamilton MJ, Moses M, Bettencourt L. 2012 Human macroecology: linking pattern and process in big-picture human ecology. Biological Reviews 87, 194-208.

43. Rousset F. 2018 An introduction to the spaMM package for mixed models.

44. Rousset F, Ferdy J-B, Courtiol A, authors (src/gsl_bessel.*) GSL. 2018 spaMM: Mixed-Effect Models, Particularly Spatial Models. See https://cran.r-project.org/web/packages/spaMM/index.html. 
45. Rousset François, Ferdy Jean-Baptiste. 2014 Testing environmental and genetic effects in the presence of spatial autocorrelation. Ecography 37, 781-790. (doi:10.1111/ecog.00566)

46. Gunderson LH, Holling CS. 2001 Panarchy: understanding transformations in human and natural systems. Island press.

47. Currie TE, Greenhill SJ, Gray RD, Hasegawa T, Mace R. 2010 Rise and fall of political complexity in island South-East Asia and the Pacific. Nature 467, 801.

48. Walker RS, Hamilton MJ. 2011 Social complexity and linguistic diversity in the Austronesian and Bantu population expansions. Proceedings of the Royal Society of London B: Biological Sciences 278, 1399-1404.

49. Carneiro RL. 1967 On the relationship between size of population and complexity of social organization. Southwestern Journal of Anthropology 23, 234-243.

50. Feinman GM. 2011 Size, complexity, and organizational variation: A comparative approach. CrossCultural Research 45, 37-58.

51. Feinman GM. 1998 Scale and social organisation: Perspectives on archaic states. In Archaic States (eds GM Feinman, J Marcus), pp. 95-134. Santa Fe: School of American Research.

52. Ember M. 1963 The relationship between economic and political development in nonindustrialized societies. Ethnology 2, 228-248.

53. Turchin P et al. 2018 Quantitative historical analysis uncovers a single dimension of complexity that structures global variation in human social organization. Proceedings of the National Academy of Sciences 115, E144-E151.

54. Currie TE, Mace R. 2009 Political complexity predicts the spread of ethnolinguistic groups. Proceedings of the National Academy of Sciences 106, 7339-7344.

55. Earle TK. 1987 Chiefdoms in archaeological and ethnohistorical perspective. Annual review of anthropology 16, 279-308.

56. Hassan FA. 1997 The dynamics of a riverine civilization: a geoarchaeological perspective on the Nile Valley, Egypt. World Archaeology 29, 51-74.

57. Kemp BJ. 2007 Ancient Egypt: anatomy of a civilisation. Routledge.

58. O'Connor DB. 1983 New Kingdom and Third Intermediate Period, 1552-664 BC. In Ancient Egypt: A Social History (eds BG Trigger, DB O'Connor, AB Lloyd), Cambridge: Cambridge University Press.

59. Butzer KW, Butzer KW. 1976 Early hydraulic civilization in Egypt: a study in cultural ecology. University of Chicago Press Chicago.

60. Wenke RJ. 2009 The ancient Egyptian state: the origins of Egyptian culture (c. 8000-2000 BC). Cambridge University Press Cambridge. 
Major transitions in sociopolitical complexity

61. Algaze G. 2009 Ancient Mesopotamia at the dawn of civilization: the evolution of an urban landscape. University of Chicago Press.

62. Team RC. 2014 R: A language and environment for statistical computing. R Foundation for Statistical Computing, Vienna, Austria. 2013. 